\title{
Russell's American lecture tours:
}

\section{addendum}

As a result of the generous help of Lester E. Denonn, Ken Blackwell, Thomas L. Kinney and Michael Bradie of Bowl ing Green State University, Ohio, and David W. Kraeuter of Washington and Jefferson College, Washington, Pennsylvania, am able to supply some additional information on Russell's ecture tours in 1924, 1927, 1929, 1931, and 1951. (See Russel2 6, summer 1972, pp. 6-8.) As before, I cite the newspaper issue of a particular date which establishes his presence in a certain city.

1924

$\begin{array}{lll}8 \text { April } & \text { New York } & \text { New York Times, } 9 \text { April } \\ 17 \text { May } & \text { I thaca, N.Y. } & \text { Ithaca Journal-News, 19 May } \\ 19 & \text { Buffalo, N.Y. } & \text { BuffaZo Express, 20 May }\end{array}$

1927

29 Sept.

15 Nov.

18

New York

New York Times, 30 Sept.

Pittsburgh Pittsburgh Post-Gazette, 16 Nov.

Bowl ing Green, 0. Bowling Green Daily Sentinel-Tribune,

1929

3 oct. Easton, Pa. New York Times, 22 Sept.

15 ? Chicago Chicago Tribune, 19 oct.

9, 10 Nov. Dallas Dallas Morning News, 10 \& 11 Nov.

11 San Antonio San Antonio Express, 12 Nov.

22 Chicago Chicago Tribune, $23 \& 30$ Nov.

1931

17 Dec.

New York New York Times, $18 \mathrm{Dec}$

New York Herald Tribune, 18 Dec. 